\title{
Eddy-covariance data with low signal-to-noise ratio: time-lag determination, uncertainties and limit of detection
}

\section{B. Langford et al.}

Correspondence to: B. Langford (benngf@ceh.ac.uk)

The copyright of individual parts of the supplement might differ from the CC-BY 3.0 licence. 
Supplementary Information: Eddy covariance data with low SNR ratio: time-lag determination, uncertainties and limit of detection.

\section{Sensible heat, isoprene, and acetone fluxes}

\subsection{Site description}

Canopy scale flux measurements of sensible heat and volatile organic compounds (VOCs) were recorded over the Bosco della Fontana nature reserve situated north of Mantova in the Po valley, Italy (45 $\left.11^{\circ} 51^{\prime \prime} \mathrm{N}, 10^{\circ} 44^{\prime} 31^{\prime \prime} \mathrm{E}\right)$ as a part of the ECLAIRE (Effects of Climate Change on Air Pollution and Response Strategies for European Ecosystems) EC FP7 project. The nature reserve is a 233 ha area of broadleaf woodland dominated by four species: Carpinus betulus, Quercus robur, Quercus rubra and Qucerus cerris. The measurement tower was situated to the south-west of a cleared area in the centre of the forest.

\subsection{Instrument setup}

VOC fluxes and concentrations were recorded using a high sensitivity Proton Transfer Reaction-Mass Spectrometer (PTR-MS, Ionicon Analytik GmbH, Austria). The PTR-MS was located in an air-conditioned cabin at the base of a $42 \mathrm{~m}$ open lattice walk-up tower. Air was sub-sampled from a PFA (O.D. 1/2", I.D. $9 \mathrm{~mm}$ ) inlet line which ran from just below a Gill HS sonic anemometer mounted at $32 \mathrm{~m}$ above ground level, $5 \mathrm{~m}$ above the canopy top, to the cabin below. Data were logged from the sonic anemometer and the PTR-MS onto a single laptop using a program written in LabVIEW (National Instruments, USA).

The PTR-MS operating conditions were controlled so that the reduced electric field strength (the ratio of the electric field strength, $E$, to the buffer gas number density, $M$ was kept to $122 \mathrm{Td}\left(1.22 \times 10^{-19} \mathrm{~V} \mathrm{~m}^{-2}\right)$. The drift tube temperature, pressure and voltage were set to $0.21 \mathrm{KPa}, 45{ }^{\circ} \mathrm{C}$ and $550 \mathrm{~V}$ respectively. Measurements followed an hourly cycle with the instrument measuring zero air for 5 minutes followed by 25 minutes of flux measurements, 5 minutes scanning the full mass spectrum and a final 25 minutes of flux measurements. While in flux mode 11 protonated masses were monitored at $m / z 21,33,39,45,59,61,69,71,73,81$ and 137. These masses were assigned to the hydronium ion isotope, methanol, the water cluster isotope, acetaldehyde, acetone, acetic acid, isoprene, methyl vinyl ketone (MVK) and methacrolein (MARC), methyl ethyl ketone (MEK), a monoterpene fragment and monoterpenes respectively. An instrumental dwell time of $0.2 \mathrm{~s}$ was used for both $\mathrm{m} / \mathrm{z} 21$ and 39 for the other masses a dwell time of $0.5 \mathrm{~s}$ was applied, resulting in a total measurement cycle of 4.9 seconds.

Calibration of the PTR-MS was performed using a gas standard containing isoprene, acetone, and 15 other volatile organic compounds (VOCs) at a concentration of approximately 1 ppmv (Ionicon Analytic GmbH, Austria). 
61

\subsection{Time-lag calculation}

A constant prescribed time-lag was chosen by plotting a histogram of the empirical time-lags for isoprene, which had the largest observed fluxes and thus the cleanest cross-covariance functions. Each individual isoprene time-lag was determined by searching for the absolute maximum in the cross-covariance between isoprene mixing ratios and vertical wind velocity measurements (MAX method). Figure S1 displays a clear peak at $7.5 \mathrm{~s}$ which was subsequently used as the constant prescribed time-lag in this study. Many of the other measured VOCs showed weaker fluxes and hence did not display such a consistent time-lag. Consequently, the time-lags of all remaining masses were calculated by adding or subtracting the instrument dwell time from the prescribed isoprene time-lag. For example the acetic acid prescribed time-lag would be $7.0 \mathrm{~s}(7.5 \mathrm{~s}$ minus the $0.5 \mathrm{~s}$ dwell time). These measurements are presented in full by Acton et al. (2015).

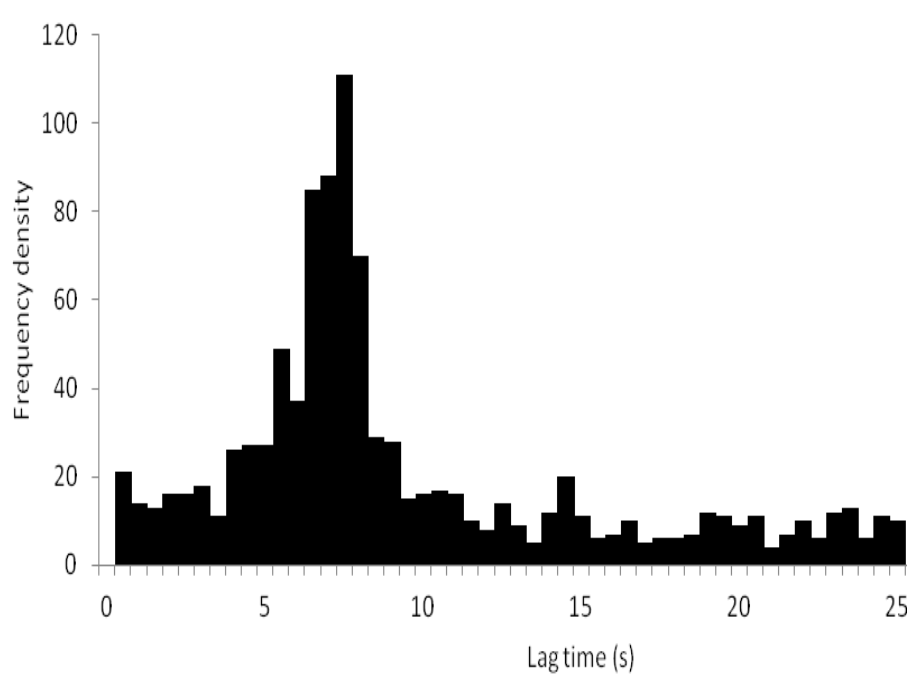

Figure S1 Histogram of the isoprene time-lags calculated by searching for the absolute maximum in the cross-covariance function.

\section{Benzene fluxes}

Here we present a brief description of the benzene flux measurements used in this manuscript. For a more complete detailed description please refer to Valach et al. (2015).

VOC flux measurements were taken from a mast on the roof of the King's College Strand building $\left(51^{\circ} 30^{\prime} 42.43^{\prime \prime} \mathrm{N} / 0^{\circ} 77^{\prime} 0.07 " \mathrm{~W}, 31 \mathrm{~m} . \mathrm{s} . \mathrm{l}\right)$ in Central London between $7^{\text {th }}$ August and $19^{\text {th }}$ December 2012 as part of the ClearfLo (Clean air for London) project. Surrounding roads supported a medium traffic volume (annual average of 30k-50k vehicles per day, DfT 2014) with the river Thames situated $200 \mathrm{~m}$ to the 
south. The site is classed as an urban site category 2 (intensely developed high density urban with 2-5 storey, attached or very close-set buildings made of brick or stone, e.g. old city core) by criteria from Oke (2006).

The inlet and CSAT3 sonic anemometer (Campbell Scientific) were mounted on a triangular tower (Aluma T45-H) at approx. $50 \mathrm{~m}(2.2 \times$ mean building height, $\mathrm{ZH}$ ) above ground level (Kotthaus and Grimmond, 2012). A $20 \mathrm{~m} \mathrm{1/2"} \mathrm{OD} \mathrm{(I.D.} 10 \mathrm{~mm}$ ) PFA tube inlet line was sub-sampled using the same high sensitivity proton transfer reaction - mass spectrometer (PTR-MS, Ionicon Analytik GmbH, Innsbruck, Austria) described above (see Lindinger et al., 1998; De Gouw and Warneke, 2007 for more detailed description of the instrument), which was used to measure VOC concentrations. Data from the sonic anemometer were logged at a frequency of 10 $\mathrm{Hz}$ and flux calculations were averaged over 25 minute periods. The mean line flow rate was $81 \mathrm{I} \mathrm{min}^{-1}$ of which the PTR-MS sub sampled air at 0.25-0.3 I $\mathrm{min}^{-1}$. Operating parameters were controlled to maintain an E/N ratio of $122 \mathrm{Td}$. The instrument was operated in MID (Multiple lon Detection) and SCAN modes in the following duty cycle: $5 \mathrm{~min}$ zero air (ZA), $25 \mathrm{~min}$ MID followed by a further $5 \mathrm{~min}$ SCAN and 25 min MID mode. During the ZA cycle air was pumped through a custom-made gas calibration unit (GCU) fitted with a platinum catalyst heated to 200 ${ }^{\circ} \mathrm{C}$ to provide instrument background values. The SCAN mode measured the concentrations of a wide range of masses (m/z $21-206$ using $0.5 \mathrm{~s}$ per m/z). In MID mode, the quadrupole scanned 11 predetermined protonated masses with a dwell time of $0.5 \mathrm{~s}$ for all but $\mathrm{m} / \mathrm{z} 21$ which was sampled at $0.2 \mathrm{~s}$. The duty cycle used comprised of the following masses: $\mathrm{m} / \mathrm{z} 21$ (indirectly quantified $\mathrm{m} / \mathrm{z} 19$ primary ion count $\left[\mathrm{H}_{3}{ }^{18} \mathrm{O}^{+}\right]$), $\mathrm{m} / \mathrm{z} 33$ (methanol), $\mathrm{m} / \mathrm{z} 39$ (indirectly quantified $\mathrm{m} / \mathrm{z} 37$ first cluster $\left[\mathrm{H}_{3}{ }^{16} \mathrm{O}^{+} \mathrm{H}_{2}{ }^{16} \mathrm{O}^{+}\right]$), $\mathrm{m} / \mathrm{z} 42$ (acetonitrile), $\mathrm{m} / \mathrm{z} 45$ (acetaldehyde) $\mathrm{m} / \mathrm{z} 59$ (acetone/propanal), m/z 69 (isoprene/furan), m/z 79 (benzene), m/z 93 (toluene), m/z 107 ( $\mathrm{C}_{2}$-benzenes) and $\mathrm{m} / \mathrm{z} 121$ ( $\mathrm{C}_{3}$-benzenes).

Measurements of turbulence and VOC concentrations were logged on separate computers which meant the two dat sets had to be carefully synchronised during post processing. Data synchronisation was achieved by searching for the absolute maximum in a cross-covariance function between the vertical wind velocity and the VOC concentrations. As well as correcting for drift between the two PC clocks, the cross-covariance also accounted for the time-lag between sonic and PTR-MS measurements associated with the long inlet line used. Acetone showed the clearest cross-covariances which are shown in Fig. S2. A prescribed time-lag for acetone was calculated based on the clustering of time-lags seen in Fig S2. Time-lags for all other species were derived from this prescribed time-lag ensuring to take into account the sequential nature of the PTR-MS duty cycle e.g. adding or subtracting time depending on the $\mathrm{m} / \mathrm{z}$ position relative to acetone in the PTR-MS duty cycle. 


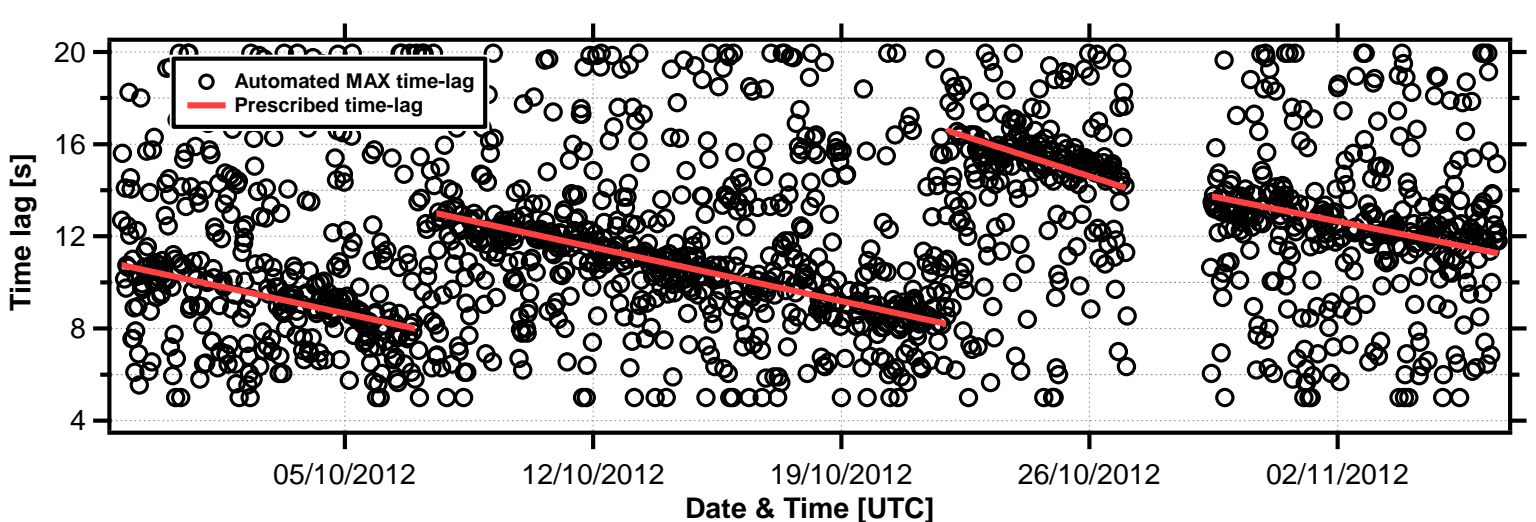

Figure S2. Time series of time-lags derived for acetone fluxes by searching for the maximum in the cross-covariance between the vertical wind velocity and acetone concentrations. The red line shows the prescribed time-lag which was fit to the data.

\section{3. $\mathrm{N}_{2} \mathrm{O}$ fluxes}

Fluxes of $\mathrm{N}_{2} \mathrm{O}$ were measured above two intensively managed grassland fields at the Easter Bush field site, Penicuik, Scotland in 2003. Concentrations of $\mathrm{N}_{2} \mathrm{O}$ were measured using a tunable diode laser (TDL) absorption spectrometer (Aerodyne Research Inc., Billerica, MA, USA) at a rate of between 5 and $7 \mathrm{~Hz}$. Further details of the instrument setup, site description and results can be found in Jones et al. (2011).

\section{Particle number fluxes}

Eddy covariance particle number fluxes were made in 2009 above Speulder Bos forest $\left(52^{\circ} 22^{\prime} \mathrm{N}\right.$. $05^{\circ} 32^{\prime} \mathrm{W}, 20 \mathrm{~m}$ asl), a mature Douglas fir forest located in the Netherlands. Measurements were made $8 \mathrm{~m}$ above the top of the $28 \mathrm{~m}$ tree canopy from a $45 \mathrm{~m}$ tall walk-up tower. Particle number concentrations were measured at 10 $\mathrm{Hz}$ using an ultra-high sensitivity aerosol spectrometer (UHSAS, Droplet Measurement Technologies, Boulder, CO, USA) and combined with vertical wind velocity measurements from a sonic anemometer (R3, Gill Instruments, Lymmington, U.K.) to give size segregated particle number fluxes (0.08 and $0.8 \mu \mathrm{m})$.

\section{Bias effects of different time-lag determination methods}

Figure S3 relates to Fig. 6 in the main manuscript and shows the average relative bias between unmodified and noisy sensible heat fluxes when calculated using a disjunct sampling interval of $5 \mathrm{~s}$. 


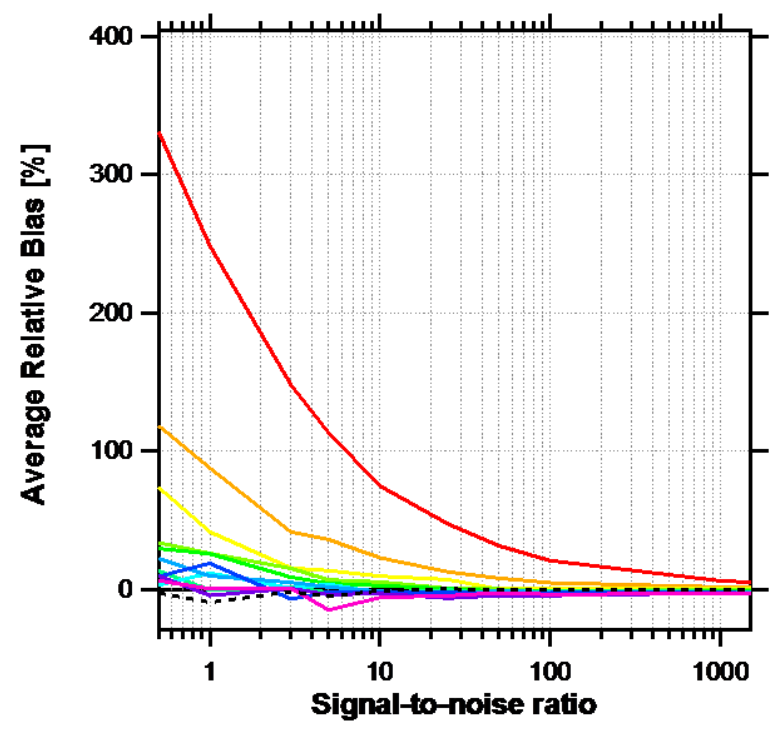

Figure S3. Average relative bias of a half-hourly flux as a function of the analyser signal-tonoise ratio for 31 days of sensible heat flux data. Fluxes were calculated using the disjunct eddy covariance method with a $5 \mathrm{~s}$ sampling interval. The signal-to-noise ratio of the temperature data was deteriorated to match pre-defined limits. The errors shown are relative to the sensible heat flux calculated using the unmodified temperature data and a constant $(0 \mathrm{~s})$ time-lag.

\section{References}

Acton, W. J. F., Schallhart, S., Langford, B., Fares, S., Valach, A., Rantala, P., Hewitt, C. N. And Nemitz, E.: Comparison of three methods to derive canopy-scale flux measurements above a mixed oak and hornbeam forest in Northern Italy, In preparation for Atmos. Chem. Phys. Discuss., 2015.

Davison B., Taipale R., Langford B., Misztal P., Fares S., Matteucci G., Loreto F., Cape J.N., Rinne J. and Hewitt C.N.: Concentrations and fluxes of biogenic volatile organic compounds above a Mediterranean macchia ecosystem in western Italy. Biogeosciences, 6, 1655-1670, 2009

de Gouw, J. and Warneke, C.: Measurements of volatile organic compounds in the Earth's atmosphere using proton-transfer-reaction mass spectrometry, Mass Spectrometry Reviews, 26, 223-257, 2007.

Jones, S. K., Famulari, D., Di Marco, C. F., Nemitz, E., Skiba, U. M., Rees, R. M., and Sutton, M. A.: Nitrous oxide emissions from managed grassland: a comparison of eddy covariance and static chamber measurements, Atmospheric Measurement Techniques, 4, 2179-2194, 2011.

Kotthaus, S., \& Grimmond, C. S. B.: Identification of Micro-scale Anthropogenic $\mathrm{CO}_{2}$, heat and moisture sources - Processing eddy covariance fluxes for a dense urban environment. Atmospheric Environment, 57, 301-316. doi:10.1016/j.atmosenv.2012.04.024, 2012. 
174 Lindinger, W., Hansel, A., and Jordan, A.: On-line monitoring of volatile organic 175 compounds at pptv levels by means of proton-transfer-reaction mass spectrometry 176 (PTR-MS) - Medical applications, food control and environmental research, Int. J. 177 Mass Spectrom., 173, 191-241, 1998.

Oke, T. R.: Towards better scientific communication in urban climate, Theoretical and Applied Climatology, 84, 179-190, 2006.

181 Taipale R., Ruuskanen T.M., Rinne J., Kajos M.K., Hakola H., Pohja T., and Kulmala 182 M.: Technical Note: Quantitative long-term measurements of VOC concentrations by 183 PTR-MS - measurement, calibration, and volume mixing ratio calculation methods. 184 Atmospheric Chemistry and Physics, 8, 6681-6698, 2008

Valach A., Langford B., Nemitz E., MacKenzie A. R., and C. N., Hewitt.: Seasonal 187 trends in volatile organic compound fluxes and concentrations above central London. 188 Atmospheric Chemistry and Physics Discussions. In preparation (2015). 